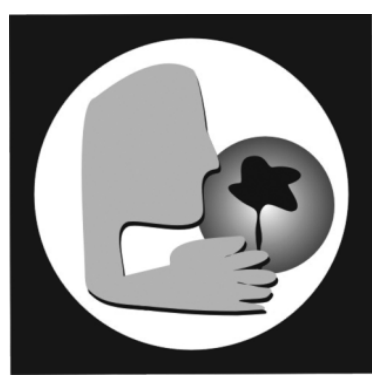

Sustentabilidade e $m$ Debate

\section{DURAMAZ, um Sistema de Indicadores de Desenvolvimento Sustentável na Amazônia}

\author{
Martine Droulers ${ }^{1}$, François-Michel le Tourneau ${ }^{2}$, \\ Stephanie Nasuti ${ }^{3}$, Florent Kohler ${ }^{4}$, Guillaume \\ Marchand $^{5}$, Anna Greissing ${ }^{6}$, Philippe Lena ${ }^{7}$, \\ Vincent Dubreuil ${ }^{8}$
}

\section{RESUMO}

Palavras-chave: Desenvolvimento sustentável, Amazônia, sistema de indicadores, populações tradicionais

Key-words:Sustainable development, Amazon, indicator system, traditional populations seus resultados.
A análise do processo de sustentabilidade representa um grande desafio científico enquanto a Amazônia constitui um verdadeiro laboratório onde estão sendo testadas inúmeras concepções desse conceito. Haveria pontos ou mecanismos comuns entre estas? Esse é o ponto que pesquisou o programa DURAMAZ, que teve como objetivo de desvendar fatores chaves, ou "determinantes" do desenvolvimento sustentável (DS) na Amazônia brasileira através da identificação dos impactos geográficos, demográficos e socioeconômicos de 13 projetos de DS. Apresentamos os pontos-chaves da metodologia, assim como algumas visões de síntese sobre a aplicação do conceito de desenvolvimento sustentável. Entender as dinâmicas internas de cada uma dessas experiências foi a meta principal, assim como entender as razões de um bom desempenho. $\mathrm{O}$ resultado final do programa de pesquisa reside na construção de um sistema de indicadores a partir de bancos de dados sistematizados (socioeconômico, demográfico/biográfico e geográfico) e na análise de

\section{ABSTRACT}

The analysis of sustainability is a big scientific challenge, especially in Amazônia, a region which has become a kind of open-air laboratory where many conceptions of what is sustainability are currently being tested. The unveiling of recurring effects in these experiments, which could constitute key factors of sustainability in the context of tropical forests, was the main objective of the DURAMAZ research project, which analyzed the local geographical, social, demographical or economic impacts of 13 projects of sustainable development throughout the Amazon. We present in this text the key points of the methodology, especially the construction of an ad-hoc indicator system, grounded on the databases elaborated from the information collected in the field, and some conclusions we were able to reach about sustainability in the Brazilian Amazon region. 
O que há de comum entre um loteamento agrícola da pós-frente pioneira, uma aldeia indígena, uma reserva extrativista ou uma área de proteção ambiental? À primeira vista, pouca coisa. Porém, apesar de pertencerem a contextos amazônicos bem diferenciados, esses lugares muitas vezes têm um ponto em comum: a aplicação, por uma comunidade, de um "projeto de desenvolvimento sustentável". Desvendar os mecanismos comuns nesse universo de experiências particulares foi o objetivo de um programa de pesquisa franco-brasileiro de quatro anos, denominado DURAMAZ, a partir do qual foi elaborado um livro que acaba de ser publicado por uma editora francesa, sob a direção de Martine Droulers e François-Michel Le Tourneau (BELIN, 2010) ${ }^{1}$.

A finalidade do presente artigo não é de resumir as 480 páginas do livro, mas sim de apresentar os pontos-chaves da metodologia que contêm a riqueza de um trabalho coletivo, pluridisciplinar e criterioso, assim como algumas visões de síntese sobre a aplicação do conceito de desenvolvimento sustentável. Dois pontos essenciais da metodologia sobressaem: a imperiosa necessidade de pesquisas de campo e a importância dada ao discurso dos atores locais.

A análise do processo de sustentabilidade representa um grande desafio científico; o termo, carregado de valores (BENETTI, 2006), é polissêmico e multidimensional e necessita o uso de uma metodologia sistêmica cruzando os dados econômicos, ecológicos e sociais, capaz de induzir princípios normativos, mas sem um aparelho de normas (THEYS, 2001). Por sua vez, a Amazônia constitui um verdadeiro laboratório onde estão sendo testadas inúmeras concepções da sustentabilidade das quais surgiram "experimentos associados à biosociodiversidade criando novas territorialidades com populações de origem étnica e/ou geográfica, diferentes técnicas e parcerias diversas" (BECKER, 2008).

O objetivo do programa DURAMAZ foi avançar na definição dos fatores chaves, ou "determinantes" do desenvolvimento sustentável na Amazônia brasileira, através da identificação dos impactos geográficos, demográficos e socioeconômicos de 13 experiências localizadas, no intuito de observar as similitudes e diferenças entre elas. Entender as dinâmicas internas de cada uma dessas experiências foi a meta principal, assim como entender as razões de um bom desempenho.

Durante os três anos de trabalho, a metodologia foi se aprimorando e os resultados progressivamente incluídos contribuíram para o enriquecimento da reflexão sobre o significado da sustentabilidade no meio rural amazônico. Nossas análises foram sempre correlatas com as condições locais, pois mais do que as performances de cada experiência, é a explicação dos resultados observados que mais interessava. Dito de outra maneira, o resultado final do programa de pesquisa reside mais na construção de um sistema de indicadores ad-hoc, do que representar uma tentativa de inovação teórica sobre o tema da sustentabilidade. Nossas referências estão se baseando na definição de Brundtland (1987), nos reajustes ecodesenvolvimentistas de I. Sachs (1993) e nos sistemas comunitários de gestão dos recursos salientados por E. Ostrom (1990).

Em resumo, as contribuições do programa DURAMAZ podem ser apresentadas em quatro pontos:

- enriquecer o estoque de conhecimentos de ciência social sobre Amazônia;

- $\quad$ entender melhor os fatores que tornam a fixação do povoamento rural da Amazônia brasileira sustentável;

- construir um sistema de indicadores a partir de bancos de dados sistematizados (socioeconô- 
mico, demográfico/biográfico e geográfico), para estabelecer medidas e padrões de comparação;

- ter uma ferramenta pedagógica no intuito de alimentar o diálogo entre os atores, os tomadores de decisões, assim como restituir às populações entrevistadas alguns resultados da pesquisa ${ }^{2}$.

\section{Treze áreas de estudo}

A seleção das experiências de desenvolvimento sustentável a serem estudadas decorria em parte do conhecimento prévio das áreas selecionadas, mas sobretudo da preocupação de cobrir o amplo leque de situações características da geografia rural Amazônica (extrativismo, agricultura familiar, agr business, áreas indígenas), e estudar pelo menos um caso em cada Estado da Amazônia legal. A escolha (intencional) de 13 casos diversos, situados em localidades bem distribuídas pelo território reflete, portanto, a grande variedade de contextos encontrados na região, mesmo que ela não possa explicar toda a complexidade das realidades amazônicas ou ser considerada como estatisticamente significadora.

De fato, mesmo se o bioma florestal é central a todas as problemáticas de pesquisa na região, o caráter de mosaico da Amazônia está sempre sublinhado (AB'SABER, 2002; PASQUIS et al., 2003). A Amazônia não é apenas um complexo mosaico de contextos econômicos, sociais e ecológicos, é também um intrincado universo de atores. Os casos estudados pelo projeto DURAMAZ revelam dois aspectos relevantes nesse sentido. Por um lado, aos atores tradicionais (índios, seringueiros e caboclos ribeirinhos) se somam novas categorias sociais, representantes da fronteira de ocupação (agricultores familiares, assentados da reforma agrária, operadores do agribusiness, madeireiros, garimpeiros, burocratas etc). Por outro lado, a presença desses diversos atores é percebida - mesmo que em escalas diferentes em quase todos os locais estudados. Esse último aspecto é relevante e revelador da configuração de um quadro social e econômico complexo, que tipifica a Amazônia como um território de convivência de setores tradicionais com novos atores. Em grande medida, é por este motivo que a Amazônia se define também como um território de conflitos e como um espaço de manifestação de relações de "cooperação" e complementariedade inesperadas (ex.: madeireiros e agricultores familiares).

A Tabela 1 apresenta as treze áreas, de tamanho bem diferenciado, com delimitação geográfica ou institucional particular, cuja localização está mapeada na Figura 1. Além dos questionários socioeconômicos a nível das unidades domésticas, a integração das informações geográficas de cada lugar estudado e a aplicação de questionários biográficos ao nível dos indivíduos foram duas originalidades metodológicas do levantamento de dados. Assim, a partir de um único protocolo de estudo seguido por cada equipe de pesquisa no campo, foi constituído um acervo de dados considerável: 900 questionários que necessitaram uma importante permanência em campo, totalizando 485 dias para os pesquisadores sênior e 650 dias para os pesquisadores júnior ${ }^{1}$. Os pesquisadores eram especialistas das ciências sociais, (com uma predominância de geógrafos) e tinham a preocupação de conhecer o funcionamento das comunidades, de entrevistar os atores chaves dos programas de desenvolvimento sustentável e de mapear em diversas escalas.

\section{EBIMAZ: perfis sócio-demográficos das populações estudadas}

As etapas de migração/estabilização são um componente determinante da vida das popula- 
ções amazônicas, tanto nas frentes pioneiras quanto nas áreas da Amazônia fluvial, pois os modos de agir destas populações estão intrinsecamente ligados aos saberes individuais e coletivos adquiridos sobre o ambiente, os quais, por sua vez, estão estreitamente atrelados ao percurso migratório do indivíduo (RIST e DAHDOUHGUEBAS, 2006). Dessa constatação surgiu a necessidade de incorporar no projeto DURAMAZ um componente para o estudo das dinâmicas migratórias características de cada local de pesquisa.

Escolhemos como ferramenta um protocolo de pesquisa "EBIMAZ" (Estudo Biográfico das Populações Amazônicas), centrado no indivíduo. Caracteriza-se como um questionário de tipo biográfico e retrospectivo, que recolhe, para todos os anos de vida do entrevistado, a sua trajetória migratória (lugar e tipo de residência), escolar e profissional; familiar (união, co-residência, filhos), assim como informações biográficas pontuais sobre os pais do entrevistado. Com ele, os eventos que compõem as três trajetórias são identificados, de forma sistemática, no espaço e no tempo (individual e histórico) e podem ser relacionados entre si. Tal dispositivo nos dava a possibilidade de estudar a fundo os comportamentos migratórios bem como de agregar outras informações (tal como a vida escolar) ao sistema de indicadores que apresentaremos a seguir. Ao total, 729 biografias foram analisadas, que agrupamos em duas coortes distintas: os res-

Tabela 1: As treze áreas de estudo.

\begin{tabular}{|c|c|c|c|c|c|c|}
\hline Contexto & & Nome in teiro & $\begin{array}{l}\text { Denominação } \\
\text { Duramaz }\end{array}$ & $\begin{array}{l}\text { Municipio / } \\
\text { Estado }\end{array}$ & $\begin{array}{c}\text { Numero de } \\
\text { famílias } \\
\text { total/entrevistadas }\end{array}$ & $\begin{array}{l}\text { Superficie } \\
\text { (ha) }\end{array}$ \\
\hline \multirow{5}{*}{ 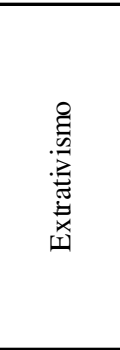 } & 1. & $\begin{array}{l}\text { Reserva de Desenvolvimento } \\
\text { Sust entável Mamirauá }\end{array}$ & RDS Mamirauá & $\begin{array}{c}\text { Uarini } \\
\text { (Amazonas) }\end{array}$ & $47 / 44$ & 22440 \\
\hline & 2. & $\begin{array}{c}\text { Projeto AgroExtrativista Chico } \\
\text { Mendes }\end{array}$ & $\begin{array}{l}\text { PAE Chico } \\
\text { Mendes }\end{array}$ & Xapuri (Acre) & $96 / 77$ & 24000 \\
\hline & 3. & $\begin{array}{l}\text { Reserva de Desenvolvimento } \\
\text { Sustent ável Iratapuru }\end{array}$ & RDS Iratapuru & $\begin{array}{c}\begin{array}{c}\text { Laranjal do Jarí, } \\
\text { (Amapá) }\end{array} \\
\end{array}$ & $35 / 34$ & 110000 \\
\hline & 4. & $\begin{array}{l}\text { Reserva de Desen volvimento } \\
\text { Sustentável Tupé }\end{array}$ & RDS T upé & $\begin{array}{c}\text { Manaus } \\
\text { (Amazonas) }\end{array}$ & $600 / 45$ & 12000 \\
\hline & 5. & Reserva extrativista do Ciriaco & RESEX Ciriaco & $\begin{array}{l}\text { Cidelândia } \\
\text { (Maranhão) }\end{array}$ & $150 / 76$ & 8084 \\
\hline \multirow{5}{*}{ 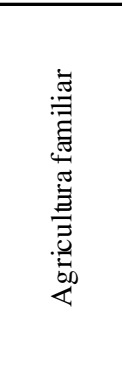 } & 6. & $\begin{array}{l}\text { Projeto de Desenvolvimento } \\
\text { Sust entável Esperança }\end{array}$ & PDS Esperança & Anapu (Pará) & $310 / 61$ & 25000 \\
\hline & 7. & $\begin{array}{c}\text { Área de de Proteção Ambiental } \\
\text { do Igarapé Gelado }\end{array}$ & $\begin{array}{l}\text { APA Igarapé } \\
\text { Gelado }\end{array}$ & $\begin{array}{l}\text { Parauapebas } \\
\text { (Pará) }\end{array}$ & $60 / 37$ & 21600 \\
\hline & 8. & $\begin{array}{c}\text { Associação Juinense Organizada } \\
\text { Para Ajuda Mútua }\end{array}$ & $\begin{array}{l}\text { Associação } \\
\text { AJOPAM } \\
\end{array}$ & $\begin{array}{c}\text { Juina (Mato } \\
\text { Grosso) }\end{array}$ & $300 / 119$ & 2585 \\
\hline & 9. & $\begin{array}{c}\text { Projetos de Assent amento } \\
\text { Palmares e Margarida Alves }\end{array}$ & $\begin{array}{l}\text { PAPalmares e } \\
\text { Margarida Alves }\end{array}$ & $\begin{array}{l}\text { Ouro Preto } \\
\text { d'Oeste } \\
\text { (Rondônia) }\end{array}$ & $568 / 60$ & 21000 \\
\hline & 10. & Projeto Ouro Verde & $\begin{array}{l}\text { Projeto Ouro } \\
\text { Verde }\end{array}$ & $\begin{array}{c}\text { Alta Floresta } \\
\text { (Mato Grosso) }\end{array}$ & $250 / 81$ & 25488 \\
\hline 岕离 & 11. & Projeto Sorriso Vivo & Sorriso Vivo & $\begin{array}{l}\text { Sorriso (Mato } \\
\text { Grosso) }\end{array}$ & $350 / 60$ & 65000 \\
\hline \multirow{2}{*}{ 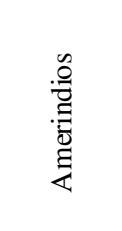 } & 12. & $\begin{array}{c}\text { Aldeia Watoriki (Terra Indígena } \\
\text { Yanomami) }\end{array}$ & W atoriki & $\begin{array}{l}\text { Barcelos } \\
\text { (Amazonas) }\end{array}$ & 30 & 50000 \\
\hline & 13. & $\begin{array}{l}\text { Aldeia Moikarako (Terra } \\
\text { Indígena Kayapó) }\end{array}$ & Moikarako & $\begin{array}{l}\text { Ourilândia } \\
\text { (Pará) }\end{array}$ & $42 / 33$ & 32374 \\
\hline
\end{tabular}




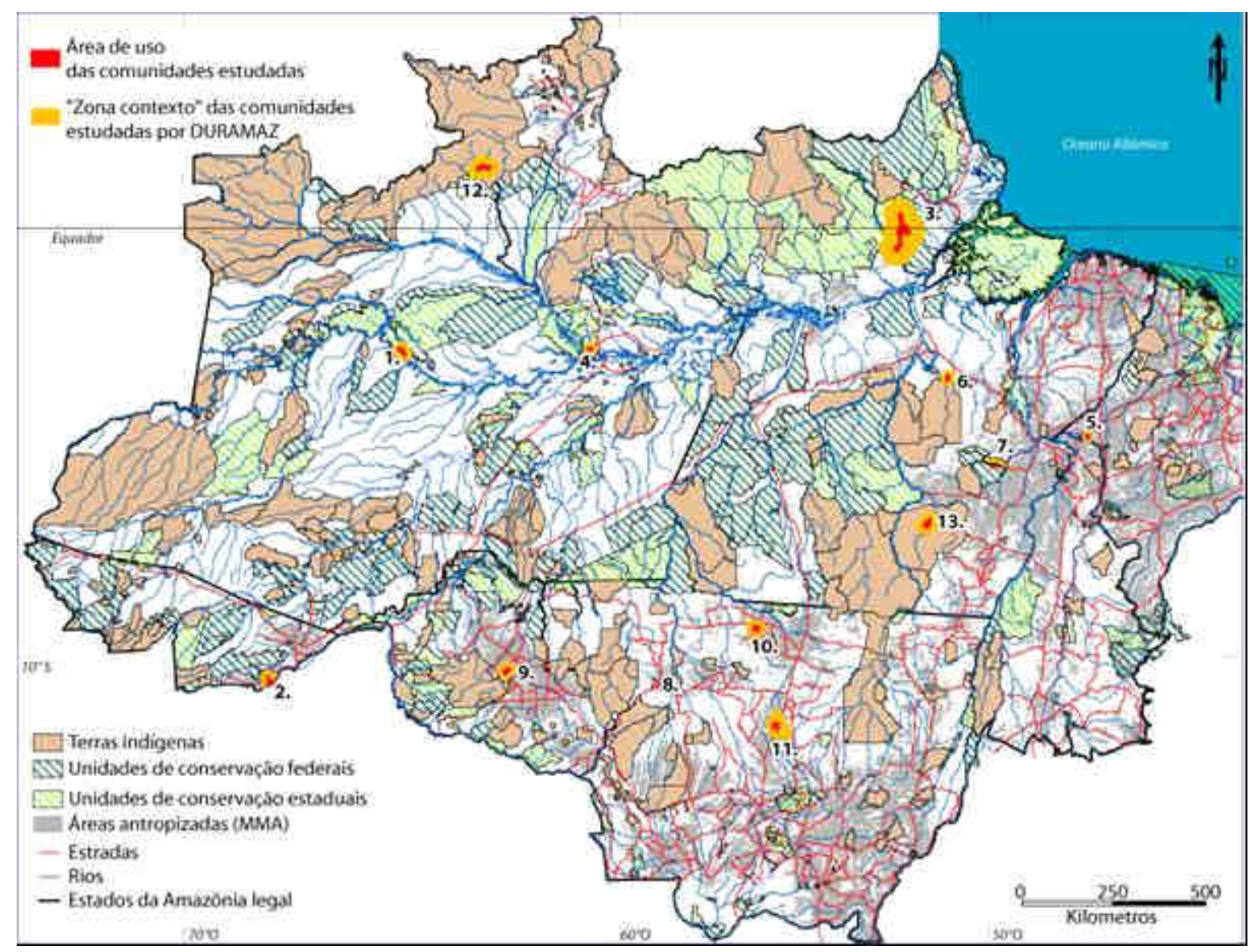

Figura 1: Localização das áreas de estudo.

ponsáveis de domicílio de mais de 45 anos e os com menos de 45 anos na data da pesquisa. Também agrupamos os sítios de estudo em quatro grupos regionais, conforme aparece na Tabela 2 .

Essa análise geracional permite acompanhar as mudanças de atividade entre as coortes. Por exemplo, na RESEX Ciriaco, 90\% dos mais de 45 anos praticam uma atividade do setor primá- rio (agricultura, extrativismo), enquanto é o caso somente para 54\% dos mais jovens. A mesma tendência pode ser observada na RDS Iratapuru (79\% contra 55\%) e na RDS Mamirauá (65\% contra 30\%). Com relação ao matrimônio, a idade se revela pouco relevante, com um número de união baixo qualquer que seja a idade, em torno de 1,2 ou 1,3 na vida do entrevistado. Por sua

Tabela 2: Classificação das comunidades de pesquisa na análise EBIMAZ.

\begin{tabular}{|c|c|c|c|c|c|}
\hline & & $\begin{array}{c}\text { Agricultura } \\
\text { moderna }\end{array}$ & $\begin{array}{l}\text { Agricultura } \\
\text { familiar }\end{array}$ & $\begin{array}{l}\text { Populações } \\
\text { extrativistas }\end{array}$ & Indígena \\
\hline \multirow{3}{*}{ Amazônia oriental } & APA Igarpé Gelado & & $\mathrm{X}$ & & \\
\hline & PDS Esperança & & $\mathrm{X}$ & & \\
\hline & Resex Ciriaco & & $\mathrm{X}$ & $\bar{X}$ & \\
\hline \multirow{4}{*}{ Amazônia meridional } & Associação Ajopam & & $\bar{X}$ & & \\
\hline & Ouro verde & & $\mathrm{X}$ & & \\
\hline & PAPalmares e Margarida Alves & & $\bar{X}$ & & \\
\hline & Projeto Sorriso Vivo & $\mathrm{X}$ & & & \\
\hline \multirow{4}{*}{ Amazônia fluvial } & PAE Chico Mendes & & & $\mathrm{X}$ & \\
\hline & RDS Irat apuru & & & $\bar{X}$ & \\
\hline & RDS Mamirauá & & & $\mathrm{X}$ & \\
\hline & RDS T upé & & & $\bar{X}$ & \\
\hline Indígenas & Aldeia Moikarako & & & & $\mathrm{X}$ \\
\hline
\end{tabular}


vez, a Amazônia fluvial se distingue com trajetórias familiares mais precoces, com entrada em união por volta dos 18 ou 19 anos, contra uma idade média de 23 anos nas outras regiões. Percebe-se que os quatro grupos se distinguem nitidamente quando se trata de analisar o número médio de filhos. As Amazônias oriental e fluvial caracterizam-se por um número de filhos ainda relativamente elevado (5 para a jovem geração, 7 para os mais de 45 anos), a taxa de fecundidade diminuindo mais rapidamente na Amazônia fluvial do que na Amazônia oriental. Na Amazônia meridional, o número de filhos é menor, com respectivamente 2 e 4 filhos.

A pesquisa EBIMAZ confirma um importante passado migratório para todas as populações amazônicas inclusas na amostra. Consegue ainda diferenciar vários padrões nas trajetórias migratórias, que variam em função do contexto de inserção. $\mathrm{O}$ estudo confirma primeiramente a diversidade de origem dos migrantes: o Nordeste para os atuais moradores da Amazônia oriental, a região Sul para os agricultores da Amazônia meridional e a bacia do rio Amazonas para os extrativistas. Todos os sítios incorporados a uma frente pioneira, que sejam de agricultura familiar ou extrativista, foram o palco de migrações particularmente intensas nos anos 70 e 80, tendência decrescente desde então. Nas zonas extrativistas da Amazônia fluvial, a atividade migratória aparece mais independente dos movimentos de massa. Os fluxos são também mais fracos, chegando à metade dos das zonas de agricultura familiar, apesar de um recente aumento nas RDS Iratapuru, RDS Tupé e na aldeia Moikarako.

Sem grande surpresa, o acesso à terra aparece como um fator explicativo da intensidade migratória, isto mas especificamente nas zonas de agricultura familiar. Permanecendo no setor primário, através da migração, muitos dos en- trevistados alcançaram o estatuto de proprietário. De forma diferente, as migrações das populações extrativistas aparecem ligadas à terra, mas também a motivos familiares. Nessas áreas, os entrevistados mudam mais de atividade, porém menos de estatuto.

EBIMAZ também revelou que a ultima migração trouxe uma estabilidade maior aos entrevistados que as etapas precedentes: em todos os locais de estudo (menos a RDS Tupé) o tempo passado no lugar atual de moradia é superior aquele das outras etapas migratórias. Porém, não se pode concluir que seriam os projetos de desenvolvimento sustentável responsáveis por esta estabilização, pois o acesso à terra é suficiente para explicar tal fato. No entanto, a questão migratória constitui um parâmetro relevante na equação da sustentabilidade: os projetos de desenvolvimento sustentável apóiam-se nos homens e nas mulheres que vivem e trabalham nas áreas estudadas, tornando-os atores centrais na medida em que são suas práticas sobre o território e suas interações com o meio-ambiente que vão determinar a sustentabilidade do lugar. Portanto, a estabilidade ou não do povoamento é um fator importante, pois ela determina sem dúvida a capacidade da população local em mobilizarse em prol dos projetos. Deste ponto de vista, e mesmo que a fixação dos pais em um local não augure do comportamento migratório das gerações seguintes, pode-se dizer que a sedentarização que começa a aparecer nos nossos lugares de estudo é um fator favorável.

\section{IDURAMAZ: um sistema de indicadores}

\section{Criação do sistema}

Com a finalidade de poder propor uma perspectiva comparativa entre os casos estudados, montamos um sistema de indicadores próprio. Esse 
passo exigiu um importante trabalho de elaboração e uma escolha criteriosa dos elementos da construção do sistema chamado pela circunstância de IDURAMAZ. Para poder tratar a diversidade das experiências situadas em contextos geográficos tão diferenciados, foi necessário uma criteriosa revisão bibliográfica da qual saíram diversas opções para medir da sustentabilidade. Depois de estudar as metodologias adotadas a nível internacional, como o índice de bem-estar das nações de Prescott Allen para ONU (2003) ou o ESI environmental sustentability index - da Universidade de Yale (JAH e MURTHY, 2003) transformado em EPI - environmental performance index - (em 2008), revisamos também os sistemas próprios da França (IFEN) e do Brasil (Indicadores de Desenvolvimento Sustentável - IDS, do IBGE) com o intuito de desenvolver um sistema próprio que fosse uma hibridação de todos esses métodos. Ao final, nossa metodologia se aproximou mais do método IDEA (Indicadores de sustentabilidade dos estabelecimentos agrícolas) do Ministério da Agricultura da França (PESCHARD et al., 2004) e do IQV (Indicadores de qualidade de vida) aplicado no meio rural brasileiro (FERNANDES et al., 1997), acrescentando a estes outras características, tal como a inclusão da percepção subjetiva do bem-estar, na combinação de índices proposta.

\section{Módulos e indicadores}

Depois dessa etapa de ampla revisão bibliográfica, começou o trabalho de converter as informações dos questionários em escalas numéricas e transformar os dados brutos em indicadores ou índices (VAN BELLEN, 2002). As variáveis brutas foram analisadas, harmonizadas, recodificadas e transformadas em 44 sub-indicadores escalonados segundo uma escala de pontuação (scoring). A maneira pela qual foi defini- da a escala dessa classificação de valores foi um ponto crucial e resultou de vários debates na equipe de pesquisa. Com objetivo de síntese e, segundo uma organização piramidal, os resultados foram depois reagrupados em 14 indicadores e, finalmente, em quatro módulos que compõem as quatro dimensões básicas da sustentabilidade que DURAMAZ explora (Figura 2).

O módulo "Qualidade de vida" conta com o maior número de indicadores (1 à 7) e 22 subindicadores; esse item inclui as preocupações cotidianas das populações rurais amazônicas assim como as dos programas ligados ao desenvolvimento sustentável. Ele reúne os dados relativos à renda, ao equipamento dos domicílios, à saúde, à educação, à inserção nos circuitos econômicos, ao isolamento das comunidades e aos meios de transporte. Os resultados variam entre 8 (Sorriso Vivo) e 3,6 (PDS Esperança), esse último caso ilustra a precariedade de condições de vida nos loteamentos recém instalados, que chegam a ser até piores que nas terras indígenas (Moikarako, 4,6).

O módulo "proteção do meio ambiente" possui três indicadores $(8,9,10)$ e 10 sub-indicadores; ele procura medir o desmatamento na zona de estudo e na zona do entorno, avaliar o respeito das áreas mais sensíveis (APP) e propor um cálculo de biodiversidade (metodologia Biodam, GUILLAUMET et al., 2009) que vai além das bases do PRODES e permite precisar as dinâmicas paisagísticas. Os resultados variam entre 8,5 para os mais preservados (Iratapuru, Esperança) e 4,5 para os menos preservados (Ciriaco, AJOPAM).

O módulo "necessidade do presente e perspectivas para o futuro" possui dois indicadores (11 e 12) e 6 sub-indicadores; ele busca medir as evoluções locais e saber se as necessidades do presente estão atendidas sem com- 
prometer as das gerações futuras. Ele procura também avaliar a percepção das mudanças e satisfação da população, saber se os pais consideram que os filhos terão um futuro no lugar e se o nível de educação que pode ser alcançado localmente atende as expectativas que eles formam para os seus filhos. Todos esses fatores contribuem, segundo a nossa hipótese, à estabilidade ou a instabilidade das comunidades: se as populações apresentam-se insatisfeitas, estarão mais propensas a recorrer à migração e não perseguir as experiências de desenvolvimento sustentável. Quatro comunidades tem resultados acima de 7 (Iratapuru, Moikarako,PDS Esperança e PAE Chico Mendes) e dois abaixo de 4 (RDS Tupé e APA Igarapé Gelado).

\section{O módulo "governança” ou “organização} social" possui dois indicadores (13 e 14) e 6 subindicadores e aborda um aspecto cada vez mais estudado (BRONDIZIO et al., 2009). No caso de DURAMAZ, esse módulo ambiciona medir a diversificação e as interações dos atores ou, de uma certa maneira, a "governança local" e o grau de envolvimento das populações em relação às ações de desenvolvimento sustentável. Os resultados são geralmente baixos, entre 6,6 e 4,2. Os melhores foram obtidos nas comunidades que possuem organizações camponesas fortes e/ou experiências anteriores (PPG7). Com esse módulo, pode-se questionar se a presença de novos atores de desenvolvimento oferecer às comunidades novas e verdadeiras oportunidades de inserção sócio-política.
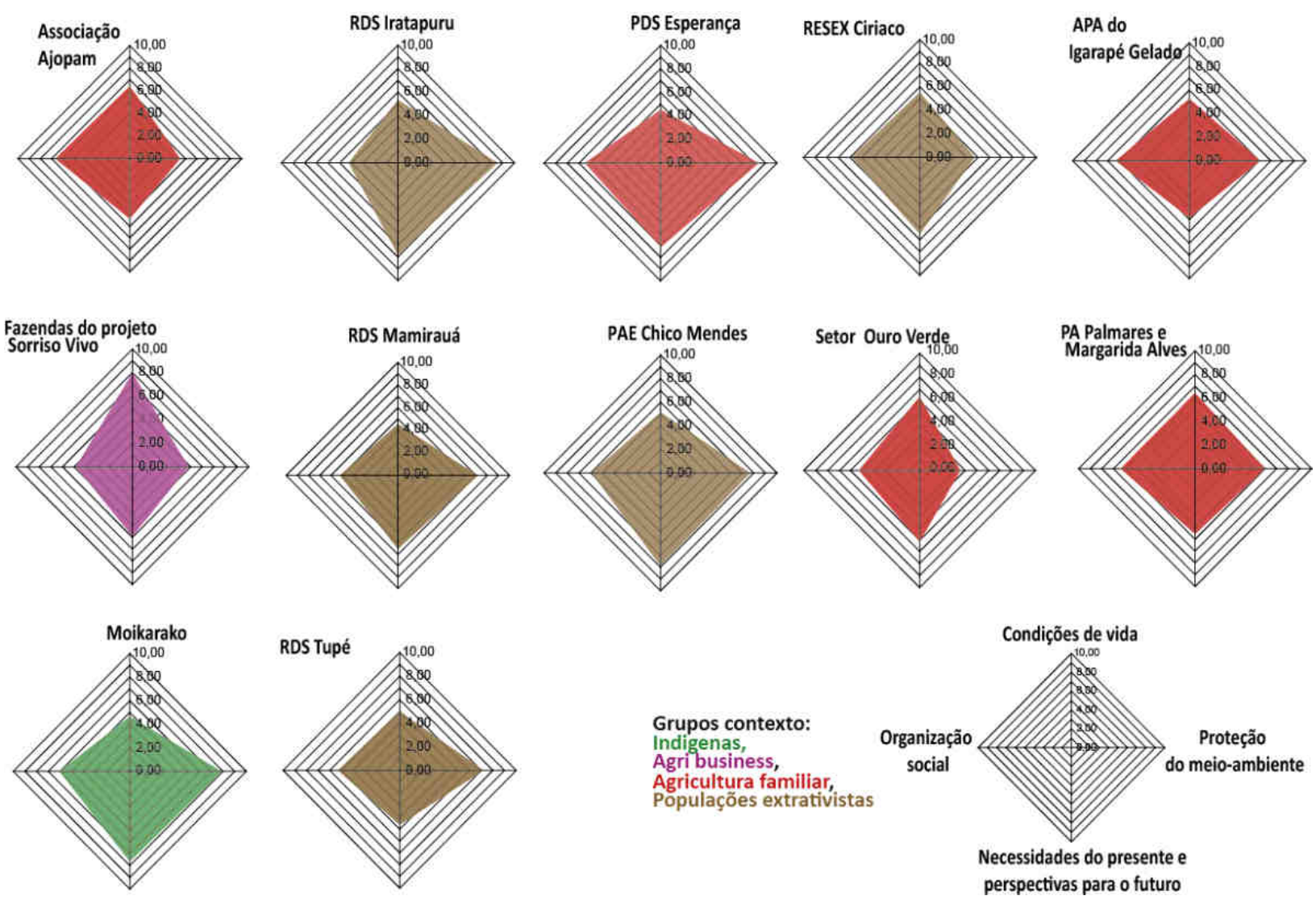

Figura 2: Resultados gráficos do sistema IDURAMAZ em 4 módulos. 


\section{Resultados e Análises}

A visão em 14 indicadores e os resultados tanto numéricos (Tabela 3) quanto gráficos (Figura 3) têm como objetivo de apontar para os contrastes entre os lugares e de descobrir os indicadores mais pertinentes que serão chamados de fatores-chaves da sustentabilidade. Comentaremos a seguir os resultados obtidos dentro do cálculo dos 44 sub-indicadores para que o leitor possa ter uma compreensão melhor dos dados que foram utilizados e das conclusões que podem ser tiradas a partir deles.

Por exemplo, a "situação financeira das unidades domésticas" (indicador $\mathrm{n}^{\circ} 1$ ) varia entre os 9 pontos de Sorriso Vivo e os 2,77 de Moikarako. Esse contraste revela as duas situações extremas de nosso universo de análise, dos mais ricos aos mais pobres. $\mathrm{O}$ total baixo na terra dos Kayapo se explica pela inexistência nesse local de uma economia monetária, o que resulte numa dependência quase total dos recursos públicos. Apesar do contraste, anota-se que o sistema foi capaz enquadrar esses casos extremos na escala de valores prevista, o que aponta um bom funcionamento do sistema de scoring e dos critérios adotados.

O resultado da "inserção nos circuitos econômicos" (indicador $\mathrm{n}^{\circ}$ 2) é menos contrastado entre 3,88 (PDS Esperança) e 6,97 (Sorriso Vivo), porque quase toda a parte produtiva e todos processos de comercialização sofrem na Amazônia de problemas de organização, enquanto a auto-subsistência domina na maioria dos projetos.

"O nível de equipamento dos domicílios" $\left(n^{\circ} 3\right)$ depende altamente do acesso à energia elétrica, que por sua vez, torna possível o uso de eletrodomésticos. Nesse ponto, a situação dos domicílios está em rápida evolução (por exem- plo, a chegada dos postes de luz na parte oriental da RDS Tupé em 2010). Na medida em que a energia elétrica aparenta ser um fator determinante de muitos outros, podemos considerar que se trata sem dúvida de um fator de permanência sustentável no lugar.

O resultado do indicador de "isolamento" $\left(n^{\circ} 4\right)$ que revela acessibilidade e isolamento é menos discriminante do que o indicador de " $h i g i$ ene e saúde" ( ${ }^{\circ}{ }^{5}$ ). Em relação a esse ultimo indicador, a RDS Iratapuru possui o índice mais baixo $(1,84)$ e Moikarako o mais alto $(8,21)$ por causa da presença do posto de saúde na Terra Indígena e da ausência da malária neste local; ao contrario, a RDS Tupé e o PDS Esperança apresentam numerosos casos dessa doença, o que explica o índice baixo desses sítios nessa categoria.

O indicador "igualdade entre os gêneros" $\left(n^{\circ} 6\right)$ agrupa dois sub-indicadores relacionados aos conjugues e a escolarização entre meninos e meninas. As comunidades de populações tradicionais (RDS Iratapuru, 8,76 e Moikarako, 7,72) apresentam bons resultados enquanto as zonas de pequena agricultura mostram resultados baixos (APA Igarapé Gelado, 3,43 e PA Palmares e Margarida Alves, 3,12), não por causa das atividades exercidas pelo conjugue, mas pelo diferencial de nível de escolaridade entre os meninos (que ajudam nas roças) e as meninas (que, sem este empecilho, cursam uma escolaridade normal).

O indicador $\mathrm{n}^{\circ} 7$ sobre o nível de educação integra dois aspectos: o tempo de acesso à escola e o atraso escolar das crianças de 11-12 anos; o resultado alto (10 na RDS Tupé) revela a proximidade e uma boa infraestrutura na área escolar, enquanto os lugares sem escola ou com escolas distantes da população apresentam resultados baixos: PDS Esperança $(1,75)$ e PAE Chico Mendes $(3,07)$. 
Tabela 3: Resultados numéricos do sistema IDURAMAZ segundo os 14 indicadores.

\begin{tabular}{|c|c|c|c|c|c|c|c|c|c|c|c|c|}
\hline & 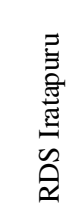 & 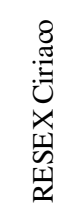 & 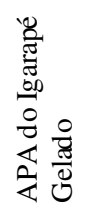 & 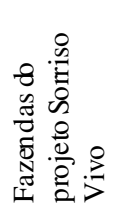 & 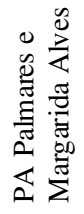 & 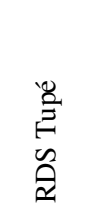 & 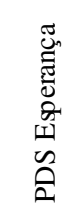 & 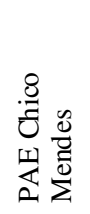 & 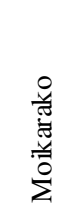 & 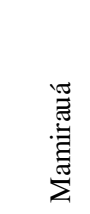 & 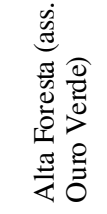 & 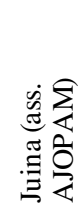 \\
\hline $\begin{array}{l}\text { 1. Situação financeira } \\
\text { dasfamílias }\end{array}$ & 6,48 & 4,58 & 5,23 & 9,00 & 6,58 & 3,79 & 3,86 & 5,33 & 2,77 & 3,16 & 6,08 & 6,87 \\
\hline $\begin{array}{l}\text { 2. Inserção nos circuitos } \\
\text { econômicos }\end{array}$ & 5,23 & 4,58 & 6,07 & 6,97 & 5,88 & 4,37 & 3,88 & 5,80 & 5,46 & 4,28 & 5,48 & 5,59 \\
\hline $\begin{array}{l}\text { 3. Nível de equipamento } \\
\text { dos domicílios }\end{array}$ & 4,68 & 5,50 & 4,12 & 8,53 & 6,71 & 5,36 & 1,74 & 3,10 & 3,68 & 4,00 & 7,42 & 5,86 \\
\hline 4. Encravamento & 3,21 & 6,47 & 5,56 & 8,57 & 7,13 & 4,41 & 4,36 & 6,50 & 2,01 & 5,75 & 6,32 & 6,13 \\
\hline 5. Higiene e saúde & 1,84 & 7,95 & 6,05 & 7,30 & 7,74 & 3,68 & 4,77 & 5,79 & 8,21 & 5,20 & 6,80 & 7,13 \\
\hline 6. Igualdade de gênero & 8,76 & 4,85 & 3,43 & 7,20 & 3,12 & 7,40 & 5,73 & 5,44 & 7,72 & 2,54 & 8,48 & 8,35 \\
\hline $\begin{array}{l}\text { 7. Educação e acesso à } \\
\text { escolaridade }\end{array}$ & 9,46 & 5,64 & 5,38 & 8,25 & 7,40 & 10,00 & 1,75 & 3,07 & 5,00 & 5,75 & 6,03 & 7,88 \\
\hline $\begin{array}{l}\text { 8. Dinâmicas do } \\
\text { meio-ambiente }\end{array}$ & 9,80 & 4,30 & 7,03 & 5,63 & 5,64 & 9,19 & 9,60 & 9,28 & 9,90 & 10,00 & 2,47 & 2,57 \\
\hline $\begin{array}{l}\text { 9. Pressões sobre o } \\
\text { meio ambiente }\end{array}$ & 8,70 & 6,17 & 5,11 & 3,97 & 6,56 & 7,45 & 7,70 & 7,19 & 6,76 & 7,57 & 4,54 & 7,79 \\
\hline $\begin{array}{l}\text { 10. Percepções e } \\
\text { práticas ambientais }\end{array}$ & 6,70 & 3,74 & 5,73 & 4,49 & 5,89 & 4,27 & 7,51 & 6,09 & 6,38 & 2,96 & 3,68 & 3,82 \\
\hline $\begin{array}{l}\text { 11. Percepção das } \\
\text { mudanças e satisfação } \\
\text { da população }\end{array}$ & 6,85 & 5,37 & 6,03 & 7,79 & 4,95 & 5,48 & 7,92 & 7,86 & 8,10 & 5,31 & 7,32 & 6,98 \\
\hline $\begin{array}{l}\text { 12. Mudanças } \\
\text { entre gerações }\end{array}$ & 8,27 & 7,07 & 4,23 & 4,93 & 5,85 & 4,17 & 6,67 & 7,88 & 7,44 & 7,08 & 5,50 & 4,47 \\
\hline $\begin{array}{l}\text { 13. Apoios } \\
\text { institucionais }\end{array}$ & 4,67 & 5,63 & 7,31 & 6,45 & 7,27 & 7,21 & 6,67 & 6,57 & 7,20 & 5,00 & 5,56 & 7,07 \\
\hline $\begin{array}{l}\text { 14. Govemançae } \\
\text { relaçóes internas }\end{array}$ & 3,77 & 6,10 & 5,34 & 3,23 & 5,52 & 3,42 & 6,61 & 5,32 & 4,89 & 5,41 & 4,95 & 6,28 \\
\hline
\end{tabular}

Em relação às dinâmicas ambientais e à atenção voltada para o meio ambiente, o sistema IDURAMAZ propõe três indicadores diferentes para analisá-los. $\mathrm{O}$ indicador $\mathrm{n}^{\circ} 8$ trata do desmatamento: sem surpresa, ele fica muito elevado no caso de comunidades extrativistas (nota acima de 9 para as RDS) e baixo nas áreas de frente pioneira (abaixo de 5 para Ouro Verde, AJOPAM). Só a Resex Ciriaco aparenta um padrão diferente do esperado para seu contexto institucional, um fato que será confirmado por outros indicadores também. $\mathrm{O}$ indicador $\mathrm{n}^{\circ} 9 \mathrm{faz}$ referência à questão das pressões sobre o meio ambiente, seguindo a linha dos estudos do índice de pressão antrópica (SAWYER, 1997) e de pegada ecológica (WACKERRNAGEL et al.,
2005), incluindo o sub-indicador referente ao tratamento dos resíduos domésticos. A inclusão deste último, de fato, modifica a hierarquia entre os sítios estudados na medida em que os bons resultados sobre a conservação da floresta alcançados pelas áreas mais afastadas acabam sendo matizados pelo tratamento inadequado do lixo que elas freqüentemente exibem. Com relação às percepções e às práticas ambientais (indicador $\mathrm{n}^{\circ} 10$ ), as comunidades localizadas em áreas de floresta preservada (RDS Iratapuru, PDS Esperança) apresentam melhores resultados, enquanto as comunidades do arco do desmatamento ficam sempre abaixo de 5. As imposições dos programas de desenvolvimento sustentável deveriam realçar o respeito do código florestal e 
do reflorestamento. Entretanto, os impactos dessas novas normas ambientais parecem ainda pouco perceptíveis.

Quanto aos indicadores "Percepção das mudanças e satisfação da população", o $\mathrm{n}^{\circ} 11$ mede o nível de satisfação em relação às transformações recentes ligadas à aplicação dos programas de desenvolvimento sustentável: alto para as populações indígenas (Moikarako, 8,10) e baixo para as comunidades onde a atividade agrícola predomina (PA Palmares, 4,95). O indicador $\mathrm{n}^{\circ} 12$, "Mudanças entre gerações", indica o posicionamento em relação à percepção que as populações têm sobre a possibilidade dos filhos terem um futuro no lugar. As comunidades agrícolas apresentam nota baixa (como 4,23 no APA Igarapé Gelado) e as comunidades na floresta obtêm uma nota alta (8,27 RDS Iratapuru), assim como as populações indígenas que privilegiam a fixação dos filhos no lugar. Vale ressaltar que essa visão do futuro é provavelmente sensível às circunstâncias: boa safra, dificuldades com a vizinhança ou a escola podem influenciar a visão das perspectivas à oferecer aos filhos.
Para apreciar a governança local, o indicador $\mathrm{n}^{\circ} 13$ aponta a força dos suportes institucionais. As comunidades mais articuladas com o exterior se sobressaem (acima de sete) APA Igarapé Gelado, RDS Tupé, PA Palmares, AJOPAM; entretanto o PAE Chico Mendes, bastante notório nacionalmente e internacionalmente, não tem uma pontuação tão elevada $(6,57)$. $\mathrm{O}$ indicador $\mathrm{n}^{\circ} 14$, relativo às relações internas das comunidades e à capacidade de se mobilizar para o DS, apresentam médias geralmente baixas; foi difícil medir a responsabilização da população nos projetos. Parece que as zonas agrícolas se beneficiam da presença do tripé sindicato-associação, local-grupo e religioso, o que gera mais dinamismo social.

\section{O processamento dos indicadores}

Para poder avaliar melhor os fenômenos recorrentes, a equipe lançou vários tratamentos estatísticos tais como análises multivariadas, das quais resultaram diversas classificações, ou análises de correlação, necessárias para identificar os fatores-chaves mais pertinentes e as intera-
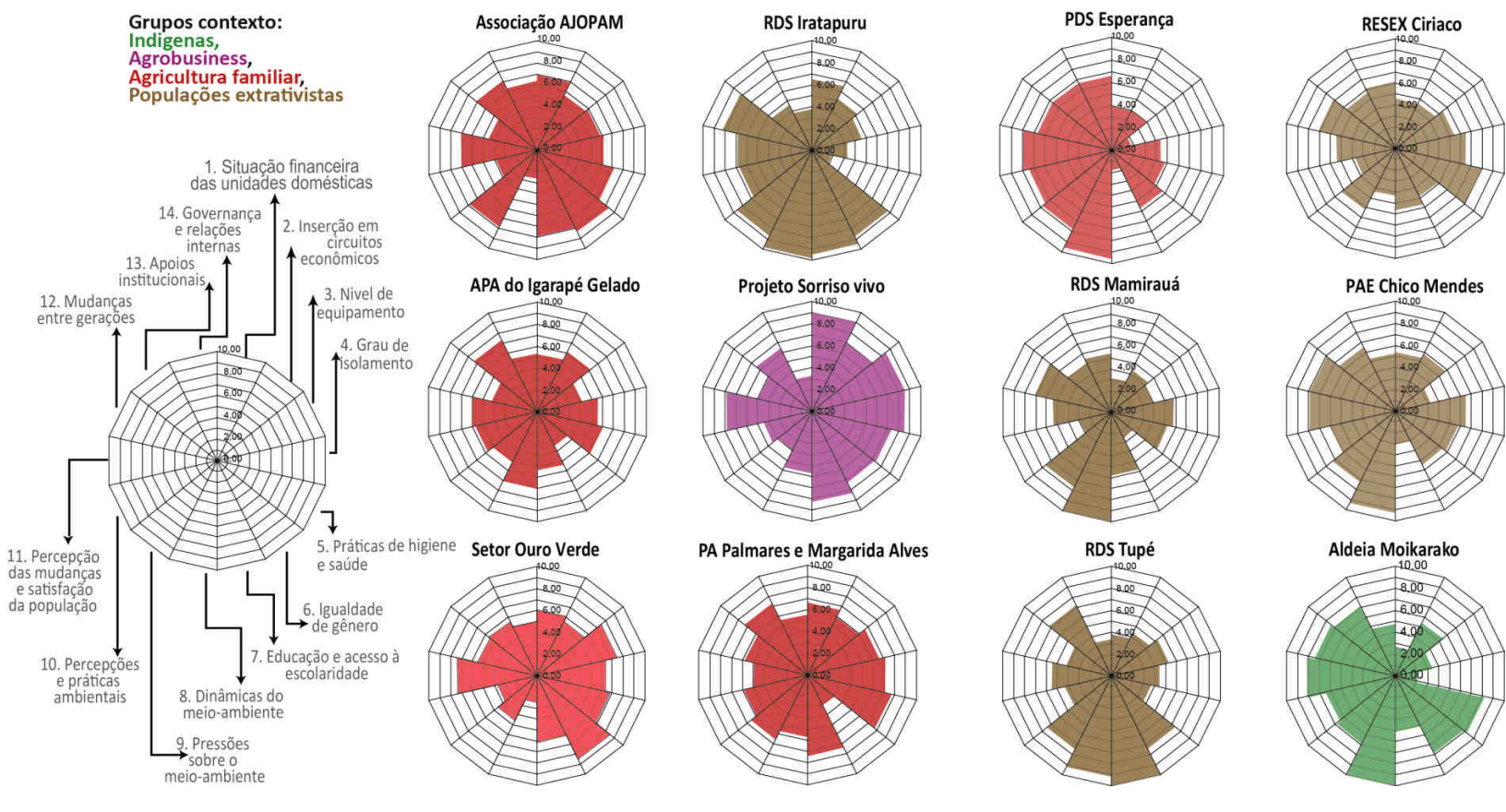

Figura 3: Resultados gráficos do sistema IDURAMAZ em 14 módulos. 
ções entre os fenômenos que interferem na aplicação de projetos de desenvolvimento sustentável. As primeiras permitiram identificar semelhanças no comportamento estatístico de vários dos sítios estudados. O resultado mais interessante desse tipo de análise foi de comprovar que a amostra de experiências de desenvolvimento sustentável estudada pelo projeto DURAMAZ, apesar da sua diversidade, pode ser resumida em duas categorias e duas comunidades isoladas. Assim, um primeiro grupo (PAE Chico Mendes, Moikarako, Mamirauá, PDS Esperança) se destaca, juntando o que podemos chamar de "comunidades florestais", exibindo uma cobertura florestal preservada e comunidades bastante desconectadas dos mercados. Apesar de compartilhar esses traços, a RDS Tupé fica um pouco distante desse grupo, provavelmente por causa das suas relações de proximidade com a cidade de Manaus. O segundo grupo reúne os perfis da agricultura familiar (Ouro Verde, AJOPAM, Igarapé Gelado, PA Palmares e Margarida Alves). Da mesma maneira que a RDS Tupé em relação ao outro grupo, as fazendas do projeto Sorriso Vivo aparecem a uma certa distância, compartilhando vários traços mas não ao ponto de serem associadas. Nesses agrupamentos, dois casos causam surpresa: o PDS Esperança, que apesar de ser um assentamento agrícola exibe um comportamento de comunidade da floresta, e a Resex Ciriaco, sempre classificada com as áreas pioneiras apesar de ser uma reserva extrativista.

Uma análise em componentes principais também trouxe pistas de reflexão para achar a ordem potencial das prioridades e avançar na identificação dos fatores-chaves da sustentabilidade. Os cálculos mostraram que um dos indicadores mais importantes é o "isolamento", ou, seja, que a acessibilidade dos territórios amazônicos continua sendo um parâmetro fundamental tan- to do ponto das relações sociais, econômicas e informacionais. Assim, as comunidades mais acessíveis, exibem os problemas ambientais mais agudos, mas também a melhor situação econômica. Assim, o ponto crucial dessa análise foi mostrar que a oposição entre preservação do meio ambiente e desenvolvimento não foi superada em lugar algum, apesar das promessas dos projetos que deviam promover um desenvolvimento sustentável. De um lado, a luta contra a pobreza permaneceu como um dos temas centrais dos programas de desenvolvimento sustentável (DS), muitas vezes antes da preservação da natureza ${ }^{1}$. Dessa forma, quando mais alto o nível de renda das famílias, maior o consumo dos recursos naturais (exemplo dos três casos do Mato Grosso). De outro lado, observa-se que as dinâmicas de reflorestamento e a implantação de sistemas agro-florestais são ainda tímidas e precisariam de fortes incentivos. Finalmente, outras inter-relações também podem ser apontadas. Assim, paradoxalmente, quanto menos isoladas, mais as comunidades tendem a se responsabilizar num programa de DS.

Numerosos estudos sobre o DS local atribuem à organização social uma importância fundamental (MOREIRA BRAGA et al., 2002; MC GRATH et al., s/d.). Na amostra DURAMAZ, a influência das redes sociais internas e externas não parece tão explicativa. Em geral, a capacidade de mobilização interna dos comunitários é fraca e eles procuram de preferência o apoio dos poderes públicos. No conjunto, as populações entrevistadas estimam que nos 5 últimos anos a situação foi melhorando, entretanto alguns acham que essas evoluções não foram suficientes (APA Igarapé Gelado, RESEX Ciriaco, RDS Mamirauá) e o impacto dos programas esta sendo matizado pelos próprios beneficiários. O comportamento dos jovens tende a demonstrar que 
as medidas tomadas não são geralmente suficientes para deixar o setor mais atrativo, e que a concorrência das cidades é forte, notadamente porque elas proporcionam empregos menos penosos.

\section{A análise dos discursos, uma metodologia pluridisciplinar}

Além do processamento estatístico dos indicadores, um enfoque especial foi dado às dimensões demográfica e antropológica no projeto DURAMAZ. Com análises complementares dos questionários e das entrevistas, foi possível estudar o registro dos discursos e das percepções, assim como designar grandes perfis sóciodemográficos.

Muitos projetos de desenvolvimento sustentável surgiram de uma mobilização social e permitiram a emergência de uma cultura política baseada no entendimento, tanto dos desafios internacionais ligados à defesa do meio ambiente na Amazônia, quanto da percepção da necessidade de manter alianças sólidas no contexto de conflitos territoriais agudos. Esses conflitos relacionados a problemas de limites e títulos de propriedades envolvem atores privados (especuladores, fazendeiros) e públicos (INCRA, IBAMA).

Para conseguir alianças, os comunitários adotam uma retórica "sustentabilista" elaborada num processo de vaivém entre a opinião pública, as mídias, os cientistas sociais e eles próprios. Nesse jogo de espelhos as responsabilidades se diluem numa nebulosa dos "povos da floresta" oprimidos, forçados a desmatar ou vender espécies protegidas pela pressão externa. No entanto muitas vezes esses discursos pré-formatados desaparecem nas entrevistas e dão lugar a outras falas que mostram o abismo entre a imagem de guardiões da floresta dessas comunidades e as suas reais percepções do meio ambiente. Por exemplo, colhe-se depoimentos desse tipo: "Eu penso dessa forma: pra quem estuda ela, tudo bem, a cobra serve. Pra quem vive aqui, ela não serve. Quem vê uma tem medo: não tou nem aí, é faca, é machado. Mas quem sabe se no futuro, não vai servir? Pros nossos filhos, nossos netos vender. Tudo o que tem vida nessas matas aqui, ela serve, ela vai servir." (comunitário, Mamirauá). Nesse tipo de discurso aflora também nas expressões do tipo "caçar só pra comer", "a gente respeita a floresta", ou definições comuns "sustentar sem derrubar", "preservar", "luta", "união".

Em relação aos danos à biodiversidade, podemos dizer que a consciência ambiental dos ribeirinhos e caboclos ainda está em gestação. Na RDS Mamirauá, por exemplo, numerosas espécies desapareceram ou são ameaçadas por causa da caça intensa ou prolongada: lontra, peixe-boi, boto, pirarucu e outras espécies. A rarefação, seguida pelo desaparecimento de um animal, é um fenômeno dificilmente apreensível sem estudo sistemático. De fato, ficar raro, e logo raramente visto, influi na percepção dos moradores: acostuma-se a não avistar um animal raro, e quando este finalmente desaparece, tal desaparecimento passa despercebido (KOHLER, 2011).

\section{Como é percebido o desenvolvimento sustentável?}

Considerando que a participação da população local é central na implementação de um projeto de desenvolvimento sustentável, tentamos entender de qual forma os moradores das comunidades estudadas percebem essa denominação. Perguntamos aos entrevistados se eles já tinham ouvido falar de "desenvolvimento sustentável" e, neste caso, se poderiam dar uma definição pessoal desta noção. 
Os resultados foram analisados de maneira quantitativa, no intuito de identificar as principais palavras-chave e, qualitativa, para avaliar os referenciais e significados usados em contextos geográficos e também semânticos e ideológicos diferenciados. Estes vão claramente além da simples interpretação de "sustentar sem derrubar" promovida por grande parte das ONGs. As definições estão construídas a partir de elementos concretos, pois, para ser apropriado localmente, o conceito de desenvolvimento sustentável precisa encontrar uma transcrição na realidade tangível do entrevistado.

De um modo geral, as dimensões ambientais e econômicas predominam. $\mathrm{O}$ desenvolvi- mento sustentável é diretamente associado à existência do meio-ambiente, porém, geralmente sob um ponto de vista utilitarista (os recursos naturais como opção econômica). A percepção do meio-ambiente aparece sempre com ênfase, mesmo se numerosas práticas predatórias se mantêm. De fato, as populações adotaram estrategicamente o discurso pró-ambientalista dos atores das entidades públicas e privadas que os acompanharam na implementação de iniciativas de desenvolvimento sustentável. Uma pergunta colateral, "quem é responsável pelo desenvolvimento sustentável?" confirma este ponto em todos os casos, pois muitos entrevistados colocaram esta responsabilidade nas entidades que implan-

Tabela 4: Freqüência de citação das principais palavras-chave.

Leitura: As palavras-chave mais citadas ( $>10 \%$ das respostas) aparecem em negrito. Em linha: a cor amarela destaca o local de pesquisa onde a palavra-chave foi a mais evocada. Em coluna: o quadro azul designa a palavrachave de maior importância em cada local de pesquisa.

\begin{tabular}{|c|c|c|c|c|c|c|c|c|c|c|c|c|c|}
\hline & & 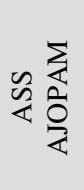 & 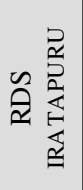 & 范 & 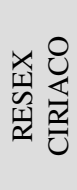 & 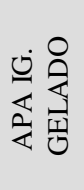 & 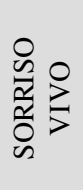 & 恣怘 & 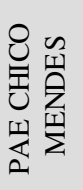 & 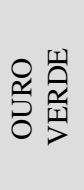 & 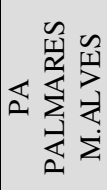 & 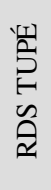 & 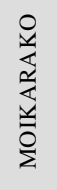 \\
\hline \multirow{7}{*}{ 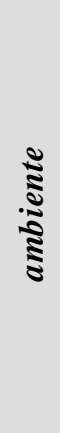 } & Floresta, mata & & 27,3 & 43,3 & & & 4,5 & & $\mathbf{5 5 , 8}$ & 8,6 & 12,2 & 27 & 67 \\
\hline & Natureza & 5,7 & 36,4 & 13,3 & 33,3 & & 4,5 & 17,9 & & 5,2 & 12,2 & 9 & \\
\hline & Meio-ambiente & & & & & 30,4 & 59,5 & & & & 26,6 & & \\
\hline & Reserva & & 7,7 & & 11 & & & 28 & & & & 23 & \\
\hline & Recursos & & 13,6 & 16,7 & & 13 & & 21,4 & & & 9,8 & & \\
\hline & $\begin{array}{c}\text { Destruir, desmatar, } \\
\text { derrubar }\end{array}$ & & 21 & 36,6 & 11,1 & 8,7 & 24,3 & & & & 17,1 & 54 & \\
\hline & Preservar, proteger & & 10,5 & 15 & & & & 7,1 & 19,2 & & & & \\
\hline \multirow{2}{*}{ 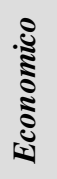 } & Produzir, produção & & & & & & 43,2 & & 17,3 & 43,1 & 87,8 & & \\
\hline & Sustentar & & & & 22,2 & & & 17,9 & & & 12,2 & 14 & \\
\hline $\begin{array}{l}\stackrel{8}{0} \\
\stackrel{0}{5}\end{array}$ & Familia & 15,7 & & & 14,3 & 26,1 & & 5,3 & & 5,2 & 17,1 & & \\
\hline$\frac{8}{\sqrt[3]{\pi}}$ & Govemo & & & 45 & 11 & & & & & 12,1 & & & \\
\hline
\end{tabular}


taram os projetos, mas raramente nas próprias comunidades.

Neste sentido, o desenvolvimento sustentável não parece ser percebido como uma espécie de filosofia ou uma forma de envolvimento, mas sim como a expressão dos benefícios concretos (recebidos ou a receber) atribuídos à comunidade ou aos indivíduos. Segundo as definições das próprias populações, os camponeses se acham mais sustentáveis que os fazendeiros e os índios se consideram como verdadeiros detentores da sustentabilidade; mas até onde?

A Tabela 4 apresenta as principais palavraschave (11 no total) que foram evocadas, isto é, presentes em pelo menos $5 \%$ das definições e evocadas no mínimo em três locais de pesquisa. Estes elementos foram reagrupados em categorias analíticas (primeira coluna), que reproduzem os pilares clássicos da definição do desenvolvimento sustentável.

Percebemos a prevalência de palavras referindo-se ao meio-ambiente e aos recursos naturais. Muitas vezes são citadas as espécies de valor comercial (castanha do Pará, açaí, babaçu) para evocar a preservação (GREISSING, MARCHAND, NASUTI, 2009). O termo "floresta", muito utilizado, representa ora um valor econômico, como no caso de PAE Chico Mendes (madeira certificada), ora um serviço ambiental garantido pelo governo, caso do PDS Esperança. O meio ambiente pode ser mencionado como uma entidade ontológica através da evocação do ecossistema que o designa e/ou através das ações (predatórias ou preservatórias) do homem sobre a natureza.

A dimensão econômica aparece em um segundo tempo, e vem sendo citada de duas formas: as palavras-chaves relativas à "produção" quer agrícola ou extrativista - são expressas como uma finalidade em si ou como uma ferramenta para sustentar a família, "sem dinheiro, não sustenta ninguém". O uso sistemático da palavra família informa sobre a unidade econômica pertinente para os entrevistados na aplicação do desenvolvimento sustentável. Uma definição resume o dilema entre a vontade de preservar e a necessidade de produzir: "Aqui não tem nada de desenvolvimento. Só sustentável mesmo".

Foi oportuno adicionar a dimensão política do desenvolvimento sustentável nesta tabela, pois a palavra-chave "governo" apareceu repetidamente, mais frequentemente no PDS Esperança, na Resex Ciriaco e no Projeto Ouro Verde. Nestes três casos, o governo foi espontaneamente evocado, ilustrando o fato de que os entrevistados concebem o desenvolvimento sustentável somente em uma lógica de parceria, na qual o governo deve intervir para que possa acontecer.

\section{Unidade da problemática, diversidade dos campos de pesquisa}

Ao final desse percurso de quatro anos de pesquisa, elaboração e consolidação de dados, numa visão sintética dos debates entre geógrafos, sociólogos e antropólogos, dois eixos de reflexão merecem ser destacados: o primeiro destaca as ambigüidades da noção de "comunidade" e o segundo enfatiza sobre as interações territoriais decorrentes da aplicação de programas de desenvolvimento sustentável.

\section{Comunidades, tradição e transição}

Apesar de ser muito utilizado, o conceito de comunidade local, parte integrante do conjunto de iniciativas de desenvolvimento sustentável na Amazônia, não deixa de ser ambíguo. Por exemplo, a confusão se mantém entre comunitário e coletivo em relação às populações rurais: os grupos humanos podem apresentar um 
grau de coesão social forte em um território até bem definido, mas sem modos de organização social necessariamente coletivos. Muitas vezes, a noção de comunidade é utilizada de maneira oportunista, uma vez que esse estatuto é valorizado, até requerido, para se beneficiar de programa de desenvolvimento sustentável (seguindo a ideologia dos projetos integrados de desenvolvimento e conservação - IPDC - pregados pelas instituições internacionais desde os anos 1990). De fato, como está evoluindo a definição de "comunidade"? Quem está dentro ou fora? As comunidades rurais não são homogêneas, mas sim atravessadas por diferenciações sociais e geracionais. Os membros mais velhos têm concepções clássicas das necessidades (terra, serviços básicos); ao contrário, as populações mais jovens que estiveram em contato com a cidade e reivindicam mais acesso (transporte, energia). Em todo caso a intermediação dos órgãos públicos é indispensável e nesse sentido as comunidades se organizam para ter os acessos que valorizam o sentido de coletividade.

O mito do tradicional continua forte. Muitas ações do desenvolvimento sustentável tendem a favorecer as populações com um estatuto particular. Mas quem são as populações tradicionais? Essas que praticam atividades mais antigas, pouco modernas? De fato, novas articulações se operam com a modernização (ARAÚJO, 2009): valorização comercial dos produtos da floresta, multiplicação das intervenções publicas, implicação das empresas. Nesse contexto emergem novas territorialidades nas quais as populações tradicionais oscilam entre a defesa dos direitos recém obtidos e uma interação maior com os atores do desenvolvimento regional. Essas novas relações exigem um período de aprendizagem tanto das estruturas quando dos fluxos.
Em todo caso a intermediação dos órgãos públicos é indispensável. Além do mais, o espaço de produção e reprodução das práticas paternalistas e clientelistas persiste e se mantém baseado no caráter assistencialista observado de longa data nos projetos de desenvolvimento no Brasil (BURSZTYN, 1984). A possibilidade de "captura" política dos resultados de ações assistenciais fica como um fato concreto tanto nas zonas tradicionais quanto nas áreas de ocupação consolidada. No seminário de restituição organizado em Brasília (outubro de 2009) foram emitidas reclamações contra excessos burocráticos e avaliações repetitivas. Em consequiência parece mais simples recorrer a um político para fazer avançar os projetos; como foi relatado: "finalmente vamos procurar um político!". De fato, com ele a transação se faz pelo voto, enquanto as outras entidades pedem a conta. Ademais, podemos constatar uma certa tendência a uma intervenção maior das ONG na Amazônia, que assume também claramente um papel paternalista.

\section{Interações territoriais e sustentabilidade}

O trabalho executado pela equipe DURAMAZ permitiu uma contribuição ao estudo da sustentabilidade do povoamento rural da Amazônia brasileira. Móveis durante muito tempo e recentemente migrantes, as populações estão se estabilizando. Será essa fixação um fator de sustentabilidade tanto social quanto ambiental? Três constatações podem explicar esse fenômeno da estabilização da população: as migrações circulares estão cada vez mais reduzidas, o crescimento de centros e serviços urbanos retém mais os jovens e a extensão das áreas protegidas bloqueia novos desmatamentos. Entretanto, as populações se fixam em função das suas características próprias e seus modos de integra- 
ção; assim como a estabilidade dos índios e das comunidades extrativistas seria sustentável? Poderia ultrapassar a atual geração, ou essa dos seus filhos, no contexto de dinamismo demográfico e de processos de aculturações? Será que os colonos fixados nos loteamentos rurais encontram uma real estabilidade agrícola enquanto a diversificação das atividades caracteriza as pós-frentes pioneiras (Mato Grosso, Maranhão, sudeste do Pará)?

Encarar o papel das relações de parentesco e das estratégias familiares foi também abordado nas análises EBIMAZ, mostrando que a razão da ultima migração reside principalmente no acesso à terra, mas também por razões familiares. Além do mais, é essa ultima etapa que procura de fato mais estabilidade ${ }^{1}$. De qualquer modo, as entrevistas mostraram como a percepção e, mais ainda, a eficácia do conceito de desenvolvimento sustentável variam de um caso ao outro, embora o uso do termo tende geralmente à ser consensual e apropriado pelas populações de maneira plástica.

A sustentabilidade das instalações humanas fica também dependente dos macro-contextos regionais nos quais a ocupação esta modificando os biomas. Uma nova regionalização emerge: a Amazônia Legal delimitada nos anos 1950 (5 milhões de $\mathrm{km}^{2}$ ), tende à ser progressivamente abandonada para privilegiar as operações de proteção ao bioma ainda completamente Amazônico (3,5 milhões de $\left.\mathrm{km}^{2}\right)$. De fato, existe uma distinção fundamental entre a Amazônia florestal (menos de $1 \mathrm{hab} / \mathrm{km}^{2}$ ) e aquela do Arco do povoamento com populações rurais densas e diferenciadas.

Seguindo essa distinção, uma síntese dos modelos e trajetórias de sustentabilidade pode ser apresentada em um gráfico (Figura 4) organizado na forma de triângulo à partir de quatro grandes sistemas bioregionais ${ }^{2}$ com características bem marcadas: uma Alta Amazônia florestal e fluvial que pode ser dividida entre uma Alta Amazônia encravada e uma Alta Amazônia conectada (ao zoneamento, ao mercado); bem como teria duas pós-frentes pioneiras, uma tradicional (marcada por estruturas sociais nordestinas) e outra mais marcada por influencia do coração econômico do sudeste do Brasil. A cada grande sistema corresponde um modelo de desenvolvimento que combina de maneira diferenciada os atores e as práticas. Na Alta Amazônia, florestal e fluvial, o papel do setor público e das ONG ambientalistas se destaca; o zoneamento protege o isolamento relativo das comunidades sem excluir as formas paternalistas e assistencialistas das relações sociais. Do outro lado, na bioregião da pós-frente pioneira, onde os operadores privados exercem um papel crescente, a pequena agricultura familiar adapta sua estratégia para combinar as ferramentas localizadas do desenvolvimento sustentável proveniente tanto dos atores públicos regionais (Estados, municípios) quanto do mercado (nichos, certificação produto). Portanto esse grupo (seis casos), apesar da mobilização de vários instrumentos (Resex, APA, PA) e da localização em bioregiões mais bem conectadas, apresenta fragilidades. Qual é o papel do fator demográfico (migração, crescimento natural) sobre a vulnerabilidade de um sistema de desenvolvimento não estabilizado demograficamente e que continua a se regular, como está fazendo há trinta anos, pelo consumo do espaço? (DROULERS e BROGGIO, 2001).

Mesmo se o programa DURAMAZ não tinha como objetivo elaborar cenários prospectivos, a interrogação sobre as grandes linhas de possíveis futuros há 20 ou 30 anos, com atores bem diferentes desses de hoje, fica aberta e esti- 
Bioregiões amazônicas, atores e modelos locais de sustentabilidade

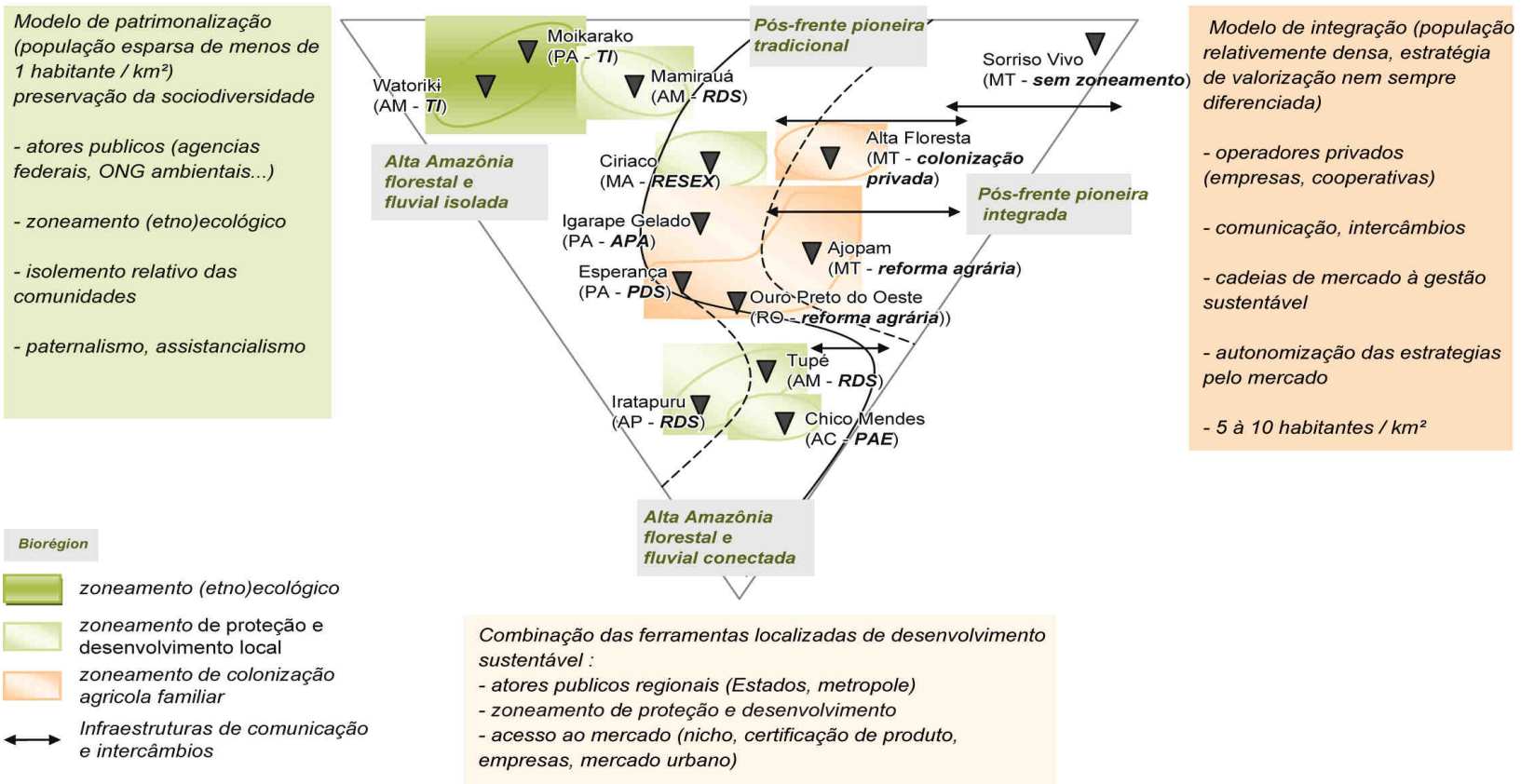

Figura 4: Trajetória dos modelos locais de sustentabilidade.

mulante. Prosseguir com o sistema IDURAMAZ, que aparece como uma ferramenta poderosa situacional e classificatória irá permitir a identificação das sinergias e dos antagonismos nas comunidades rurais amazônicas no caminho da sustentabilidade, e poderá servir de guia nas tomadas de decisão.

\section{Autores}

Martine Droulers, geógrafa, doutora pela Universidade de Paris Sorbonne Nouvelle, Centro de Documentação e Pesquisa sobre as Américas (CREDA), Centro Nacional da Pesquisa Cientifica (CNRS) / Universidade de Paris 3, Paris, França, droulers@univ-paris3.fr

François-Michel Le Tourneau, geógrafo, doutor pela Universidade de Marne-la-Vallé, Livre docente na universidade de Paris Sorbonne Nouvelle, Centro de Documentação e Pesquisa sobre as Américas (CREDA), Centro Nacional da Pesquisa Cientifica (CNRS) / Universidade de Paris 3, Paris, França, fmlt@fmlt.net
Stéphanie Nasuti, geógrafa, doutora pela Universidade de Paris Sorbonne Nouvelle, Centro de Documentação e Pesquisa sobre as Américas (CREDA), Centro Nacional da Pesquisa Cientifica (CNRS) / Universidade de Paris 3, Paris, França, stephanie.nasuti@univ-paris3.rr Anna Greissing, geógrafa, mestre pela Universidade de Paris Sorbonne Nouvelle, Centro de Documentação e Pesquisa sobre as Américas (CREDA), Centro Nacional da Pesquisa Cientifica (CNRS) / Universidade de Paris 3, Paris, França, annagreissing@gmail.com

Florent Kohler, antropólogo, doutor pela Universidade de Tours, livre docente pela Ecole Pratique des Hautes Etudes, Centro de Documentação e Pesquisa sobre as Américas (CREDA), Centro Nacional da Pesquisa Cientifica (CNRS) / Universidade de Paris 3, Paris, França, florent.kohler@gmail.com

Guillaume Marchand, geógrafo, doutor pela Universidade de Paris Sorbonne Nouvelle, Centro de Documentação e Pesquisa sobre as Américas (CREDA), Centro Nacional da Pesquisa 
Cientifica (CNRS) / Universidade de Paris 3, gaelmarch@yahoo.fr

\section{Referências Bibliográficas}

AB'SABER, A. Bases para os estudos dos ecossistemas da Amazônia brasileira. Estudos Avançados, vol. 16, $\mathrm{n}^{\circ}$ 45, 2002, p. 7-30.

ARAÚJO, R. De la "communauté" aux "populations traditionnelles". Nuevo Mundo Mundos Nuevos, Coloquios. Disponivel em : http://nuevomundo.revues.org/index56593.html. 2009.

BECKER, B. K. Um futuro para a Amazônia. São Paulo: Oficina de textos, 2008. 150 p. BENETTI L, B. Avaliação do índice de desenvolvimento sustentável do mio de Lages (SC) através do método do painel de sustentabilidade. Thèse de doctorat de l'Université de Santa Catarina, 2006. 215 p.

BERG, P. Reinhabiting a separate country, a bioregional anthology of Northern California. San Francisco: Planet drum books, 1978. 220 p. BRONDIZIO, E. S.; OSTROM, E.; YOUNG, O. J. Connectivity and the Governance of Multilevel Social Ecological Systems: The Role of Social Capital. Annual Review of Environment and Resources, 34, 2009. p. 253-278

BURSZTYN, M.; SAYAGO, D. A. V.; TOURRAND, J. F. Amazônia: cenas e cenários. Brasília: Editora Universidade de Brasília, 2003, v.1. 380 p.

BURSZTYN, M., O poder dos donos. Petrópolis: Vozes, 1984.178 p.

DALY, H. E.; COBB, Jr. J. B. For the Common Good: Redirecting the Economy toward Community, the Environment and a Sustainable Future. Boston: Beacon Press, 1989. 534 p.

DROULERS, M. ; BROGGIO, C. L'espace et le développement au Brésil: de la géophagie à la géosophie? Revue Tiers Monde, $\mathrm{n}^{\circ} 167$, juilsept. 2001, pp. 673-688.

FONSECA， I. F.; BURSZTYN, M. A Banalização da Sustentabilidade: reflexões sobre governança ambiental em escala Local. Sociedade e Estado, Brasília, v. 24, n. 1, p. 17-46, jan./abr. 2009.

FERNANDES, A.V.; SILVA, L.M.; KHAN, A.S. Reserva Extrativista do Rio Cajari. Sustentabilidade e Qualidade de vida. Revista de Economia e Sociologia Rural, vol 35, $n^{\circ} 3$, 1997. p. 119-140.

GREISSING, A. ; MARCHAND, G. ; NASUTI,

S. Protéger la forêt et ses traditions grâce à la certification commerciale? Trois exemples en aires protégées d'Amazonie brésilienne. Colloque international Localiser les produits: une voie durable au service de la diversité naturelle et culturelle de Sud?, MAB-unesco, IRD-CIRAD, Paris, 9-11, juin 2009.

GUILLAUMET, J.-L. ; LAQUES, A.-E. ; LÉNA, P. ; DE ROBERT, P. La spatialisation de la biodiversité: un outil pour la gestion durable des territoires. Bondy: IRD, coll. « latitude $23 », 2009,127 \mathrm{p}$.

JAH, R.; MURTHY, K.V.B. A critique of the environmental sustainability index. Australian national University Division of economics. Working paper, 33 p. Online: http:// pa pers.s s r n c o m/sol $13 /$ papers.cfm?abstract $\mathrm{id}=380160.2003$.

KOHLER, F. Diversité culturelle et diversité biologique: une approche critique fondée sur le modèle brésilien. In Natures, Sciences, Sociétés. (no prelo). 2011.

LE TOURNEAU, F. M. ; GREISSING, A. ; KOHLER, F. Iratapuru et la noix du Brésil: une expérience de durabilité en Amazonie brésilienne. Cybergéo, article ${ }^{\circ}$ 432. 2008. 1-20 pp.

LOBATO RIBEIRO, A. Modelo de indicado- 
res para mensuração do desenvolvimento sustentável na Amazônia. Tese de doutorado. Belém, Universidade Federal do Pará. 2002. 375 p.

MAC GRATH, D. G.; NEPSTAD, D.; STICKLER, C. Smallholders, rural development and REDD in the Brazilian Amazon. The Woods hole research center reports. Online: http:// www.whrc.org/ s.d.

MMA. PPG-7. Subprograma Projetos Demonstrativos. Estudos da Amazônia: avaliação de 20 projetos. Série Experiências PDA, n 5, 2004. $80 \mathrm{p}$.

MOREIRA BRAGA, T.; GONÇALVES DE FREITAS, A. P. Índice de sustentabilidade local: uma avaliação da sustentabilidade dos municípios do entorno do Parque Estadual do Rio Doce (Minas Gerais). In: Encontro da Associação Brasileira de Estudos Populacionais (ABEP), 13 édition, 4-8 novembre 2002, Ouro Preto (Minas Gerais), 16 p.

PASQUIS, R. (Coord.); FERREIRA NUNES, E.; LE TOURNEAU, F. M.; MACHADO 1.; MELLO N. A. de. As Amazônias, um mosaico de visões sobre a região. Brasília: Banco mundial-CDS/UNB, 2003. 44 p.

PESCHARD, D.; GALAN, M.B.; BOIZARD,

$\mathrm{H}$. Tools for evaluating the environmental impact of agricultural practices at the farm level: analysis of 5 agri-environmental methods. Actes du colloque OCDE expert meeting on farm management indicators for agriculture and the environment, 8-12 mars 2004, NouvelleZélande.

RESCOTT-ALLEN, R. (édition anglophone en 1997) Le bien-être des nations, índice par pays de la qualité de vie et de l'environnement. Paris: ESKA, 2003. 368 p.

RAISG (Rede Amazônica de Informação socioambiental Georeferenciada). Mapa da
Amazônia 2010 - Áreas protegidas e territórios indígenas. São Paulo: ISA, 2010.

RIST, S.; DAHDOUH-GUEBAS, F. Ethnosciences - A step towards the integration of scientific and indigenous forms of knowledge in the management of natural resources for the future. Environment, Development and Sustainability, vol. 8, $\mathrm{n}^{\circ}$ 4, 2006. p. 467-493. SACHS, I. Ecodesenvolvimento: crescer sem destruir. Trad. de E. Araujo. São Paulo: Vértice, 1981.

SAWYER, D. Índice de pressão antrópica: uma proposta metodológica. Brasília, 1997.

SEBILLE, P. ; ARNAULD DE SARTRE, X. ; DROULERS, M. Rapport de recherche, Action Concertée Incitative. ACI - Société et culture dans le développement durable, Dynamique de peuplement et développement durable en Amazonie. Enquête biographiques en Amazonie Brésilienne, EBIMA 2004-2005. CREDAL Université Sorbonne Nouvelle Paris 3, Paris, 2005. 85 p.

THEYS, J. A la recherche du développement durable: un détour par les indicateurs. In: JOLLIVET, M. (Dir.). Le développement durable, de l'utopie au concept. Elsevier Ed., 2001.

VAN BELLEN, H. M. Indicadores de sustentabilidade: uma análise comparativa. Thèse de doctorat en ingénierie de production, Universidade Federal de Santa Catarina, 2002. $235 \mathrm{p}$.

WACKERNAGEL, M.; MONFREDA, C.; MORAN, D.; WERME, R. P.; GOLDFINGER, S.; DEUMLING, D.; MURRAY, M. National Footprint and Biocapacity Accounts 2005: The underlying calculation method, Global Footprint network. Disponível em: http:// www.rrcap.unep.org/uneptg05/outline/synthesis/ footprint method paper\%5b1\%5d.pdf, 2005. 


\section{Notas}

${ }^{1}$ DROULERS, M ; LE TOURNEAU, F.-M. (Eds). L'Amazonie brésilienne et le développement durable. Paris: Belin, 2010 . 480 p.

${ }^{2}$ Um seminário de restituição dos resultados foi organizado na Universidade de Brasília (CDS/ UnB) nos dias 14 e 15 de outubro de 2009. Dois representantes de cada comunidade foram convidados pelo programa para refletir com a equipe de pesquisadores sobre os dados apresentados.

${ }^{3}$ No total nas pesquisas participaram 18 pesquisadores Sênior (permanecendo no campo uma media de 12 dias) e 13 pesquisadores Júnior (permanecendo no campo uma média de 55 dias).

${ }^{4} \mathrm{Na}$ análise do funcionamento das redes de atores, Chartier e Van Tilbeurgh ressaltam a impregnação da mensagem da teologia da libertação com referência a um escudo de valores, incluindo a procura de formas sociais mais cooperativas. Assim os projetos de DS têm frequentemente como objetivo financiar uma cooperativa integrada num projeto socioambientalista maior (PAE Chico Mendes, RESEX Ciriaco, RDS Iratapuru, APA Igarapé Gelado) onde os líderes foram impregnados, até formados, pelos princípios da teologia da libertação, mas, de fato, em ruptura com o sistema desenvolvimentista dominante na Amazônia.

${ }^{5}$ Seria interessante de comparar as trajetórias migratórias dos agricultores incluídos nos projetos de Desenvolvimento Sustentável e com as trajetórias de outras famílias vizinhas que não fazem parte, afim de avaliar o real impacto desses projetos (SÉBILLE et al., 2005).

${ }^{6}$ Nas quais a população, consciente dos elementos da natureza da região na qual ela vive, consegue re-estabilizar, segundo os princípios da "ecologia adaptativa", os sistemas antropizados. O bioregionalismo (BERG, 1978) aposta no fator tempo e nas estruturas políticas renovadas. 